\title{
Corrosion Inhibition of Carbon Steel by Imidazolium and Pyridinium Cations Ionic Liquids in Acidic Environment
}

\author{
Magdy A.M. Ibrahim, ${ }^{* 1,2}$ Mouslim Messali, ${ }^{1}$ Ziad Moussa, ${ }^{1}$ Abdullah Y. \\ Alzahrani, ${ }^{1}$ Saleh N. Alamry, ${ }^{3}$ Belkheir Hammouti ${ }^{4}$ \\ ${ }^{1}$ Chemistry Department, Faculty of Science, Taibah University, Al Madinah Al Mounawara, \\ 30002 Saudi Arabia \\ ${ }^{2}$ Chemistry Department, Faculty of Science, Ain Shams University, Abbassia, Cairo, Egypt \\ ${ }^{3}$ Physics Department, Faculty of Science, Taibah University, Al Madinah Al Mounawara, \\ 30002 Saudi Arabia \\ ${ }^{4}$ LCAE-URAC18, Faculté des Sciences, Université Mohamed Premier, B.P. 4808, \\ 60046 Oujda, Morocco
}

Received 11 April 2011; accepted 25 November 2011

\begin{abstract}
New imidazolium-based ionic liquids and some pyridinium-based ionic liquids, were tested as corrosion inhibitors of steel in $1.0 \mathrm{M} \mathrm{HCl}$ using potentiodynamic polarization, linear polarization and weight loss methods. The obtained results showed that all of the four ILs are good inhibitors for steel in $1.0 \mathrm{M} \mathrm{HCl}$ and the inhibition efficiency increased with increasing the inhibitor concentration. All of the ILs act as mixed-type inhibitors. Obtained results from Tafel polarization, linear polarization and weight loss are in good agreement with each other. The adsorption of the four ILs inhibitors, obey the Langmuir adsorption isotherm. From the adsorption isotherm, values of $\Delta \mathrm{G}_{\mathrm{ads}}$ for the adsorption process were calculated. The effect of temperature on the corrosion behavior of steel in presence of $1 \times 10^{-3} \mathrm{M}$ of compound II was studied in the temperature range $298-338 \mathrm{~K}$.
\end{abstract}

Keywords: corrosion inhibitor, electrochemical techniques, ionic inhibitor, adsorption.

\section{Introduction}

Acid solutions are widely used in industrial acid cleaning, acid descaling, acid pickling, and oil well acidizing, requiring the use of corrosion inhibitors in order to minimize their corrosion attack on metallic materials. The use of organic compounds containing oxygen, sulfur and especially nitrogen, to reduce

\footnotetext{
* Corresponding author. E-mail address: imagdy1963@hotmail.com
} 
corrosion attack on steel has been studied in some details [1-7]. The development of new corrosion inhibitors of non-toxic nature, which do not contain heavy metals and organic phosphates, is very important [8]. The inhibitors can decrease the dissolution rate of metals in acids, affecting the kinetics of the electrochemical reactions which constitute the corrosion process. Adsorption of inhibitor on the metal surface will change the structure of the electric double layer. The adsorption itself depends to a great extent on the molecular structure. Previous investigations showed that the inhibition efficiency is improved predominantly by increasing the molecular surface area and influenced by the position of the substituents as well [9-11]. For planar molecules with very similar molecular surface areas the adsorption properties are also function of the electronic structure of the molecule [12].

Table 1. Ionic liquids.

Compound

Although ILs are expected to be good candidates as corrosion inhibitors because of their environmentally friendly characteristics in addition to their unique properties [13-15], little investigations have been found in literature [16,17]. Zhang et al. [18] have investigated the behavior of alkylimidazolium ionic liquids for steel in acidic medium. It was found that ILs exhibited excellent inhibition performance for mild steel in acidic solution. Imidazolium compounds are reported to show corrosion resistant behavior of copper [19], steel [20, 21] and aluminum [22]. It is found that the action of such inhibitors depends on the specific interaction between the functional groups and the metal surface, due to the presence of the $-\mathrm{C}=\mathrm{N}$ - group and electronegative nitrogen in the molecule.

The objective of the present work was to study the applicability of four ILs namely: 3-(4-ethoxy-4-oxobutyl)-1-ethylimidazol-3-ium bromide (I) and 1-ethyl3-phenethylimidazol-3-ium bromide (II), 1,1'-(propane-1,3-diyl)bis(4-methylpyridinium)dibromide (III), and 1,1'-(butane-1,4-diyl)bis(4-methylpyridinium) dibromide (IV), as corrosion inhibitors for carbon steel in $1.0 \mathrm{M} \mathrm{HCl}$ (Table 1). It 
is also aimed to predict the thermodynamic feasibility of adsorption of the ILs inhibitor molecules on steel surface and to study their adsorption behavior.

\section{Experimental methods \\ Chemical synthesis}

Materials

The reagents: imidazole (99\%), ethyl 4-bromo butyrate (96\%), (2bromoethyl)benzene, 4-picoline, 1,3-dibromopropane and 1,4-dibromobutane were purchased from Aldrich and used as received. All solvents were of HPLC grade.

\section{Measurements and equipments}

All new compounds were synthesized and characterized by ${ }^{1} \mathrm{H}$ NMR and ${ }^{13} \mathrm{C}$ NMR spectroscopies. ${ }^{1} \mathrm{H}$ NMR $(400 \mathrm{MHz})$ and ${ }^{13} \mathrm{C}$ NMR (100 MHz) spectra were obtained in DMSO at room temperature. Chemical shifts $(\mathrm{d})$ were reported in ppm to a scale calibrated for tetramethylsilane (TMS), which is used as an internal standard. The LCMS spectra were measured with a Micromass, LCT mass spectrometer. The microwave-assisted reactions were performed using a controllable single-mode microwave reactor, CEM Discovery, designed for synthetic use. The reactor is equipped with a magnetic stirrer as well as a pressure, temperature and power controls. The maximum operating pressure of the reactor is $20 \mathrm{bar}$. The power and temperature range are 15-300 $\mathrm{W}$ and 60-250 ${ }^{\circ} \mathrm{C}$, respectively.

Microwave assisted synthesis of imidazolium ionic liquids

New environmentally friendly imidazolium-based ionic liquids, I and II, were prepared for the first time by using microwave irradiation in short duration of time with quantitative yields.

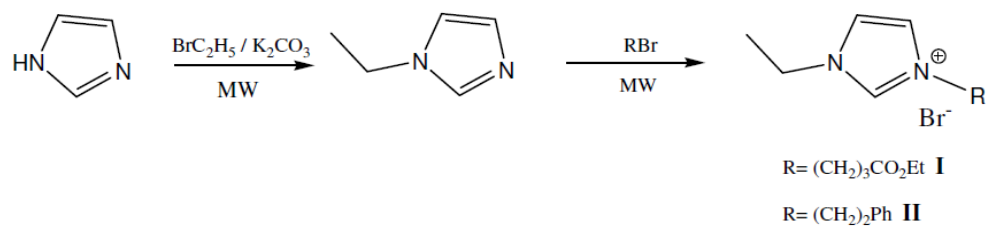

Scheme 1. N-alkylation of N-ethylimidazole under microwave irradiation (MW).

3-(4-ethoxy-4-oxobutyl)-1-ethylimidazol-3-ium bromide (I)

$N$-ethylimidazole (1 g, $0.0104 \mathrm{~mol})$ and ethyl 4-bromobutyrate $(2.03 \mathrm{~g}, 0.0104$ mol) and $10 \mathrm{~mL}$ of toluene were placed in a microwave reactor vessel and irradiated for 20 minutes at $100{ }^{\circ} \mathrm{C}$. The crude product was washed a few times with dry ethyl acetate and dried overnight in a vacuum at $70{ }^{\circ} \mathrm{C}$. The yield of $\mathbf{I}$ was $92 \%$. The product was analyzed with ${ }^{1} \mathrm{H}$ NMR, ${ }^{13} \mathrm{C}$ NMR and LCMS. ${ }^{1} \mathrm{H}$ NMR (400MHz, DMSO) $\delta: 1.13(\mathrm{t}, J=7.1,3 \mathrm{H}), 1.41(\mathrm{t}, J=7.3,3 \mathrm{H}), 2.05$ (quint, $J=7.2,2 \mathrm{H}), 2.35(\mathrm{t}, J=7.5,2 \mathrm{H}), 4,00(\mathrm{q}, J=7.1,2 \mathrm{H}), 4.24(\mathrm{q}, J=7.3$, $2 \mathrm{H}), 4.28(\mathrm{t}, J=6.8,2 \mathrm{H}), 7.93-7.94(\mathrm{~d}, J=1.21 \mathrm{H}), 7.95-7.96(\mathrm{~d}, J=1.21 \mathrm{H})$, 
9.57 (s, 1H); ${ }^{13} \mathrm{C}$ NMR (100MHz, DMSO) $\delta: 14.0\left(\mathrm{CH}_{3}\right), 15.0\left(\mathrm{CH}_{3}\right), \quad 24.9$ $\left(\mathrm{CH}_{2}\right), 30.1\left(\mathrm{CH}_{2}\right), 44.1\left(\mathrm{CH}_{2}\right), 47.9\left(\mathrm{CH}_{2}\right), 59.9\left(\mathrm{CH}_{2}\right), \quad 122.1(\mathrm{CH}), 122.3$ (CH), $135.9(\mathrm{CH}), 171.8(\mathrm{C})$; LCMS: m/z $211\left(\mathrm{M}^{+}\right)$.

\section{1-ethyl-3-phenethylimidazol-3-ium bromide (II)}

$N$-ethylimidazole (1 g, $0.0104 \mathrm{~mol})$, (2-bromoethyl) benzene (1.92 g, 0.0104 mol) and $10 \mathrm{~mL}$ of toluene were placed in a microwave reactor vessel and irradiated for 20 minutes at $100{ }^{\circ} \mathrm{C}$. The crude product was washed a few times with dry ethyl acetate and dried overnight in a vacuum at $70{ }^{\circ} \mathrm{C}$. The yield of II was $91 \%$. The product was analyzed with ${ }^{1} \mathrm{H}$ NMR, ${ }^{13} \mathrm{C}$ NMR and LCMS. ${ }^{1} \mathrm{H}$ NMR (400MHz, DMSO) $\delta: 1.37(\mathrm{t}, J=7.3,3 \mathrm{H}), 3.17(\mathrm{t}, J=7.2,2 \mathrm{H}), 4.19$ (q, $J$ $=7.4,2 \mathrm{H}), 4.48(\mathrm{t}, J=7.4,2 \mathrm{H}), 7.18-7.34(\mathrm{~m}, 5 \mathrm{H}), 7.85-7.86(\mathrm{~m}, 1 \mathrm{H}), 7.86-7.87$ $(\mathrm{m}, 1 \mathrm{H}), 9.33(\mathrm{~s}, 1 \mathrm{H}) ;{ }^{13} \mathrm{C} \mathrm{NMR}(100 \mathrm{MHz}, \mathrm{DMSO}) \delta: 15.2\left(\mathrm{CH}_{3}\right), 35.6\left(\mathrm{CH}_{2}\right)$, $44.1\left(\mathrm{CH}_{2}\right), 49.8\left(\mathrm{CH}_{2}\right), 122.0(\mathrm{CH}), 122.4(\mathrm{CH}), 126.8(\mathrm{CH}), 128.5(\mathrm{CH})$, 128.7(CH), 135.7(CH), $136.9(\mathrm{C})$; LCMS: m/z $201\left(\mathrm{M}^{+}\right)$.

Microwave assisted synthesis of pyridinium ionic liquids

Although compounds III and IV have been previously reported by conventional methods [23], their preparation under microwave irradiation has never been disclosed.
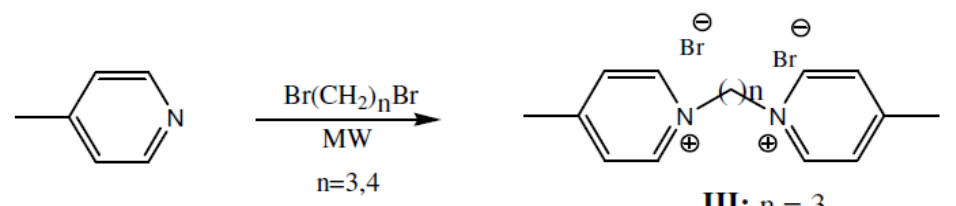

III: $\mathrm{n}=3$

IV: $\mathrm{n}=4$

Scheme 2. Synthesis of pyridinium-based ionic liquids under microwave irradiation (MW).

\section{1,1'-(propane-1,3-diyl)bis(4-methylpyridinium)dibromide (III)}

4-picoline (2 g, $0.0215 \mathrm{~mol}), 1,3$-dibromopropane $(2.1 \mathrm{~g}, 0.0107 \mathrm{~mol})$ and $10 \mathrm{~mL}$ of toluene were placed in a microwave reactor vessel and irradiated for 20 minutes at $100{ }^{\circ} \mathrm{C}$. The crude product was washed a few times with dry ethyl acetate and dried overnight in a vacuum at $70{ }^{\circ} \mathrm{C}$. The yield of III was $90 \%$. The product was analyzed with ${ }^{1} \mathrm{H} \mathrm{NMR},{ }^{13} \mathrm{C} \mathrm{NMR}$ and LCMS. ${ }^{1} \mathrm{H}$ NMR $(400 \mathrm{MHz}$, DMSO) $\delta: 2.6(\mathrm{~s}, 6 \mathrm{H}), 2.65$ (quint, $J=7.3,2 \mathrm{H}), 4.73(\mathrm{t}, J=7.5,4 \mathrm{H}), 8.03(\mathrm{~d}, J=$ $6.64 \mathrm{H}), 9.05(\mathrm{~d}, J=6.64 \mathrm{H}) ;{ }^{13} \mathrm{C} \mathrm{NMR}(100 \mathrm{MHz}, \mathrm{DMSO}) \delta: 21.4\left(\mathrm{CH}_{3}\right), 31.7$ $\left(\mathrm{CH}_{2}\right), 56.6\left(\mathrm{CH}_{2}\right), 128.4(\mathrm{CH}), 143.9(\mathrm{CH}), 159.1(\mathrm{C})$.

\section{$\underline{\text { 1,1'-(butane-1,3-diyl)bis(4-methylpyridinium)dibromide (IV) }}$}

4-picoline (2 g, $0.0215 \mathrm{~mol}), 1,4$-dibromopropane $(2.31 \mathrm{~g}, 0.0107 \mathrm{~mol})$ and 10 $\mathrm{mL}$ of toluene were placed in a microwave reactor vessel and irradiated for 20 minutes at $100{ }^{\circ} \mathrm{C}$. The crude product was washed a few times with dry ethyl acetate and dried overnight in a vacuum at $70{ }^{\circ} \mathrm{C}$. The yield of IV was $92 \%$. The product was analyzed with ${ }^{1} \mathrm{H} \mathrm{NMR},{ }^{13} \mathrm{C} \mathrm{NMR}$ and LCMS. ${ }^{1} \mathrm{H}$ NMR $(400 \mathrm{MHz}$, DMSO) $\delta: 1.92(\mathrm{~m}, 4 \mathrm{H}), 2.59(\mathrm{~s}, 6 \mathrm{H}), 4.58(\mathrm{~m}, 4 \mathrm{H}), 7.95(\mathrm{~d}, J=6.84 \mathrm{H}), 8.88$ (d, 
$J=6.84 \mathrm{H}) ;{ }^{13} \mathrm{C} \mathrm{NMR}(100 \mathrm{MHz}, \mathrm{DMSO}) \delta: 21.6\left(\mathrm{CH}_{3}\right), 27.3\left(\mathrm{CH}_{2}\right), 59.4\left(\mathrm{CH}_{2}\right)$, $128.7(\mathrm{CH}), 143.8(\mathrm{CH}), 159.3(\mathrm{C})$.

\section{Electrochemical tests}

For the weight loss measurements, carbon steel sheets of $4 \mathrm{~cm}^{2}$ size, and of chemical composition (wt $\%): \mathrm{C}=0.15 \%, \mathrm{Mn}=0.45 \%, \mathrm{Si}=0.10, \mathrm{~S}=0.05 \%, \mathrm{P} \%$ $=0.03 \%$ and the reminder Fe, were used. The samples were abraded with a series of emery papers, from a coarse grade 500 and proceeding in steps to fine grade 1500 , washed thoroughly with doubly distilled water. The cleaned samples were weighed before and after immersion in $1.0 \mathrm{M} \mathrm{HCl}$ for 4 hours in the absence and presence of various concentrations of the four ILs inhibitors.

The potentiodynamic polarization experiments were carried out in a conventional three-electrode electrochemical cell. A carbon steel cylinder pressed into a Teflon holder acted as a working electrode (WE). Its working area of $0.5 \mathrm{~cm}^{2}$ remained precisely fixed. A saturated calomel electrode (SCE) connected through a salt bridge was used as a reference electrode, while a platinum wire was used as a counter electrode. The electrode was abraded similar to that mentioned above.

Electrochemical measurements were performed using a potentiostat/galvanostat SI 1287 Solartron, software packages CorrWare 2, and CorrView 2 provided by Solartron were used to obtain the polarization curves.

The polarization curves were recorded by changing the electrode potential automatically from ca. $-0.95 \mathrm{~V}$ to $-0.75 \mathrm{~V}$ with a scan rate of $20 \mathrm{mVs}^{-1}$. From polarization curves measured using only the range $\pm 10 \mathrm{mV}$ before and after $\mathrm{E}_{\text {corr }}$, with scan rate of $1.0 \mathrm{mV} \mathrm{s}^{-1}$, the polarization resistance $R_{p}$ was evaluated. All of the experiments were triplicate to ensure reproducibility.

\section{Results and discussion}

\section{Weight loss studies}

The weight loss of steel in $1.0 \mathrm{M} \mathrm{HCl}$ in the absence and presence of various concentrations $\left(1 \times 10^{-4}-5 \times 10^{-3} \mathrm{M}\right)$ of the four ILs were obtained after $4 \mathrm{~h}$ of immersion at $25^{\circ} \mathrm{C}$. Eq. (1) determines the inhibition efficiency:

$$
\eta_{\mathrm{WL}} \%=\left(1-\mathrm{W}_{\mathrm{inh}} / \mathrm{W}\right) \times 100
$$

where $\mathrm{W}$ and $\mathrm{W}_{\text {inh }}$ are the weight loss of steel in the absence and presence of the inhibitors, respectively. The results of the four tested ILs compounds in Table 2 showed that the $\eta_{\mathrm{WL}} \%$ increases with increase in the concentration of the inhibitors. Based on the maximum inhibition efficiency, the inhibitors can be ranked as follows: II > III > I > IV. 
Table 2. Inhibition efficiencies for various concentrations of compounds I, II, III and IV for the corrosion of $\mathrm{C}$-steel in $1.0 \mathrm{M} \mathrm{HCl}$ from weight loss measurements.

\begin{tabular}{cc}
\hline Concentration $\left(\mathrm{mol} \mathrm{dm}^{-3}\right)$ & $\eta_{\mathrm{WL}} \%$ \\
\hline $1 \mathrm{M} \mathrm{HCl}($ blank $)$ & - \\
Compound I & 36.0 \\
$1 \times 10^{-4}$ & 40.0 \\
$5 \times 10^{-4}$ & 61.9 \\
$1 \times 10^{-3}$ & 71.1 \\
$5 \times 10^{-3}$ & \\
Compound II & 31.9 \\
$1 \times 10^{-4}$ & 47.5 \\
$5 \times 10^{-4}$ & 64.1 \\
$1 \times 10^{-3}$ & 80.9 \\
$5 \times 10^{-3}$ & \\
Compound III & 47.5 \\
$1 \times 10^{-4}$ & 62.5 \\
$5 \times 10^{-4}$ & 73.3 \\
$1 \times 10^{-3}$ & 80.0 \\
$5 \times 10^{-3}$ & \\
Compound IV & 50.8 \\
$1 \times 10^{-4}$ & 55.6 \\
$5 \times 10^{-4}$ & 64.5 \\
$1 \times 10^{-3}$ & 71.3 \\
$5 \times 10^{-3}$ &
\end{tabular}

Table 3. Electrochemical parameters for $\mathrm{C}$-steel in $1.0 \mathrm{M} \mathrm{HCl}$ obtained from the polarization curves at different ILs inhibitor concentrations.

\begin{tabular}{|c|c|c|c|c|c|c|}
\hline $\begin{array}{l}\text { Concentration } \\
\left(\mathrm{mol} \mathrm{dm}^{-3}\right)\end{array}$ & $\begin{array}{c}\mathrm{j}_{\text {corr }} \\
\left(\mathrm{A} / \mathrm{cm}^{2}\right)\end{array}$ & $\begin{array}{l}-\mathrm{E}_{\text {corr }} \\
(\mathrm{mV})\end{array}$ & $\begin{array}{c}\beta_{\mathrm{a}} \\
(\mathrm{mV} / \mathrm{dec})\end{array}$ & $\begin{array}{c}\beta_{\mathrm{c}} \\
(\mathrm{mV} / \mathrm{dec})\end{array}$ & $\eta_{\mathrm{pol}} \%$ & $\begin{array}{l}\text { C.R. } \\
\text { (mpy) }\end{array}$ \\
\hline $1 \mathrm{M} \mathrm{HCl}$ (blank) & 0.0040100 & 847.70 & 181.3 & 317.4 & - & 1835.3 \\
\hline \multicolumn{7}{|l|}{ Compound I } \\
\hline $1 \times 10^{-4}$ & 0.00253 & 859.6 & 144.0 & 208.5 & 36.9 & 1157.6 \\
\hline $5 \times 10^{-4}$ & 0.00247 & 8586 & 151.7 & 155.3 & 38.3 & 1132.8 \\
\hline $1 \times 10^{-3}$ & 0.00143 & 861.5 & 127.6 & 172.6 & 64.3 & 656.3 \\
\hline $5 \times 10^{-3}$ & 0.00111 & 859.5 & 110.2 & 142 & 72.3 & 509.2 \\
\hline \multicolumn{7}{|l|}{ Compound II } \\
\hline $1 \times 10^{-4}$ & 0.002796 & 825.4 & 139.9 & 165.8 & 30.3 & 1279.8 \\
\hline $5 \times 10^{-4}$ & 0.0021855 & 847.8 & 145.9 & 212.9 & 45.5 & 1000.3 \\
\hline $1 \times 10^{-3}$ & 0.0015220 & 834.7 & 87.6 & 115.4 & 62.0 & 696.6 \\
\hline $5 \times 10^{-3}$ & 0.0008115 & 826.6 & 164.9 & 146.0 & 79.8 & 371.4 \\
\hline \multicolumn{7}{|l|}{ Compound III } \\
\hline $1 \times 10^{-4}$ & 0.0021620 & 837.7 & 143.1 & 192.5 & 46.1 & 989.5 \\
\hline $5 \times 10^{-4}$ & 0.0014560 & 837.9 & 102.7 & 163.7 & 63.8 & 666.4 \\
\hline $1 \times 10^{-3}$ & 0.0010311 & 817.0 & 157.8 & 211.7 & 74.0 & 471.9 \\
\hline $5 \times 10^{-3}$ & 0.0008428 & 821.2 & 84.3 & 140.6 & 79.0 & 385.7 \\
\hline \multicolumn{7}{|l|}{ Compound IV } \\
\hline $1 \times 10^{-4}$ & 0.0020383 & 832.6 & 108.5 & 187.8 & 49.2 & 932.9 \\
\hline $5 \times 10^{-4}$ & 0.0019172 & 827.5 & 104.0 & 180.0 & 52.2 & 877.5 \\
\hline $1 \times 10^{-3}$ & 0.0014519 & 829.4 & 119.4 & 199.3 & 63.8 & 664.5 \\
\hline $5 \times 10^{-3}$ & 0.0012158 & 822.4 & 124.2 & 149.3 & 70.0 & 556.5 \\
\hline
\end{tabular}

\section{Potentiodynamic polarization curves}

Tafel plots for steel in $1.0 \mathrm{M} \mathrm{HCl}$ solution with and without various concentrations of the four ILs are shown in Figs. 1-4. Various kinetic data and corrosion parameters such as corrosion potential $\left(\mathrm{E}_{\mathrm{corr}}\right)$, corrosion current density 
$\left(\mathrm{j}_{\text {corr }}\right)$, cathodic and anodic Tafel slopes $\left(\beta_{\mathrm{c}}, \beta_{\mathrm{a}}\right)$, corrosion rate $(\mathrm{CR})$ in mpy and the inhibition efficiency $\left(\eta_{\mathrm{pol}} \%\right)$ are listed and summarized in Table 3. Corrosion current densities were obtained by linear extrapolation of the anodic and cathodic branches of the Tafel plots to the corrosion potential. The corrosion rate is determined in mils per year (mpy) using: $\mathrm{CR}=0.129 \mathrm{a} \mathrm{j} / \mathrm{n} \mathrm{D}$ [24], where CR is the corrosion rate in mpy, $a$ is the atomic weight of the metal, $\mathrm{n}$ is the number of electrons in the reduction of the metal ions, $\mathrm{D}$ is the density of the metal in $\mathrm{g} / \mathrm{cm}^{3}$, and $\mathrm{j}$ is the corrosion current density in $\mu \mathrm{A} / \mathrm{cm}^{2}$.

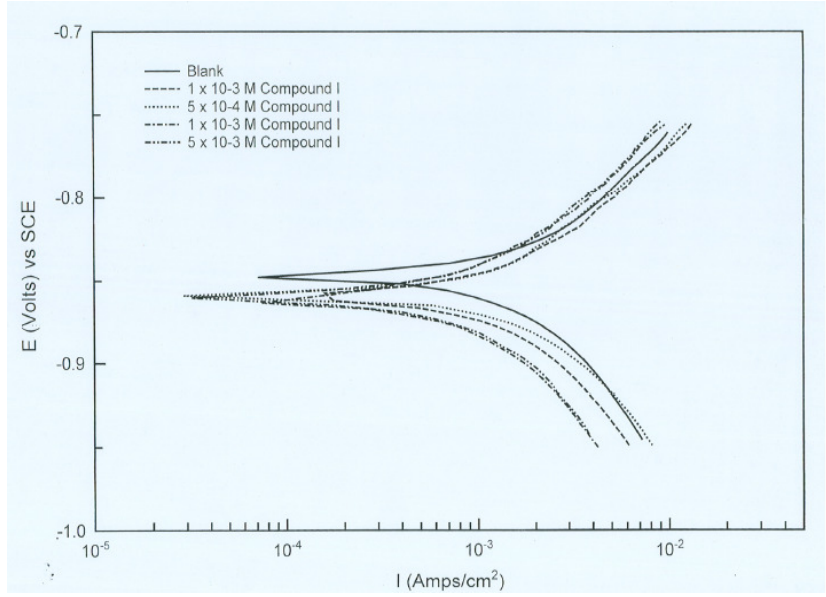

Figure 1. Potentiodynamic cathodic and anodic polarization scans for C-steel in $1.0 \mathrm{M}$ $\mathrm{HCl}$ in the absence and presence of different concentrations of compound I.

Fig. 1 represents the influence of various concentrations of compound I on the polarization behavior of steel in $1.0 \mathrm{M} \mathrm{HCl}$. In this case, the cathodic branch of the polarization curve is more affected by the addition of the inhibitor than the anodic branch. In addition, the corrosion potential in solutions containing inhibitor is shifted towards more negative values with increase of the inhibitor concentrations. This indicates that this compound acts as a mixed type inhibitor with predominant cathodic.

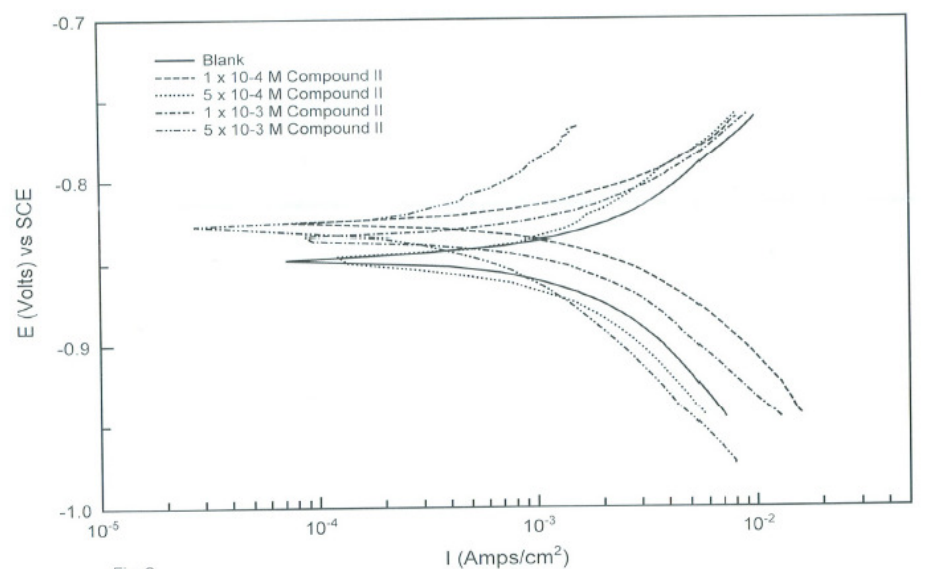

Figure 2. Potentiodynamic cathodic and anodic polarization scans for C-steel in $1.0 \mathrm{M}$ $\mathrm{HCl}$ in the absence and presence of different concentrations of compound II. 
Fig. 2 represents the influence of various concentrations of compound II on the polarization behavior of steel in $1.0 \mathrm{M} \mathrm{HCl}$. The anodic current decreased with increasing the inhibitor concentration and the corrosion potential is shifted to more positive potential indicating a mixed type inhibitor with predominant anodic. According to some researchers [25,26], an inhibitor behaves as anodic or cathodic only if displacement due to inhibitor addition is at least of $85 \mathrm{mV}$ with respect to $\mathrm{E}_{\mathrm{corr}}$ of the blank solution (absence of the inhibitor). In the present case, (compounds I and II) shift were lower than the referenced value, which suggests that experimental compounds can be defined only as mixed type inhibitors with predominant anodic.

The inhibition efficiency $\eta_{\text {pol }} \%$ at different inhibitor concentrations was calculated from the following equation:

$$
\eta_{\text {pol }} \%=\left(1-\mathrm{j}_{\text {corr }} / \mathrm{j}_{\text {corr }}^{\mathrm{o}}\right) \times 100
$$

where $\mathrm{j}_{\text {corr }}$ and $\mathrm{j}_{\text {corr }}^{\mathrm{o}}$ are the current density in the absence and presence of inhibitors, respectively. The $\eta_{\text {pol }} \%$ increases with increasing the concentration of the inhibitors. The results suggest the inhibitor molecules are adsorbed at the steel/solution interface where the adsorbed molecules partly hinder the active sites of the corrodent. The increase in $\eta_{\mathrm{pol}} \%$ observed at higher inhibitor concentration indicates that the adsorption process enhances with increasing inhibitor concentration, which leads more inhibitor molecules to adsorb on the metal surface, thus resulting large surface coverage.

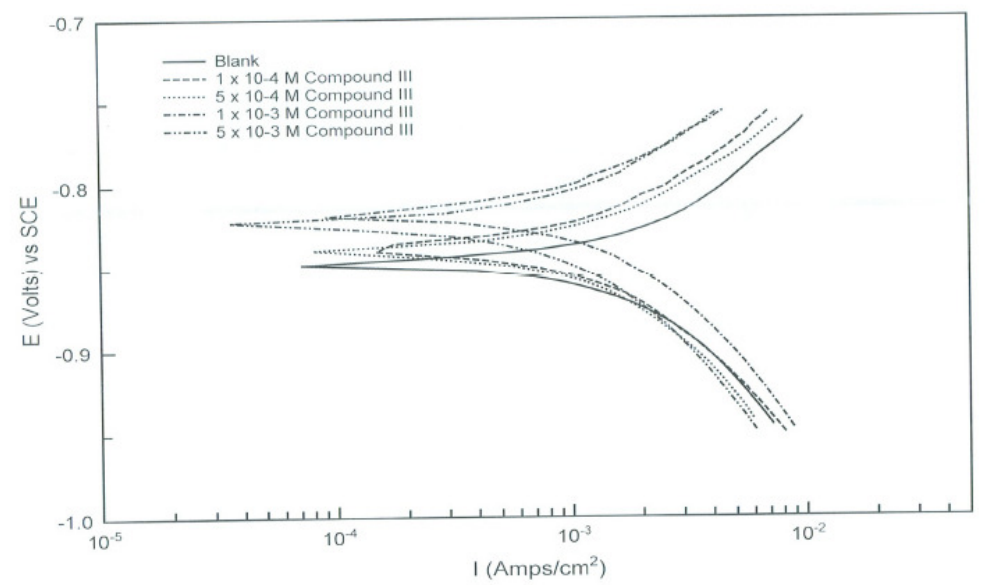

Figure 3. Potentiodynamic cathodic and anodic polarization scans for C-steel in $1.0 \mathrm{M}$ $\mathrm{HCl}$ in the absence and presence of different concentrations of compound III.

Figs. 3 and 4 represent the influence of adding various concentrations of compound III and compound IV, respectively, on the polarization behavior of steel in $1.0 \mathrm{M} \mathrm{HCl}$. It is observed that the presence of ionic liquid affected both the anodic dissolution of steel and the cathodic hydrogen evolution reaction in 1.0 $\mathrm{M} \mathrm{HCl}$. These compounds decreased the corrosion current density and shifted $\mathrm{E}_{\mathrm{corr}}$ towards more noble potential values, indicating that the inhibitors act as mixed type. 
It is of practical importance to study the inhibitor behavior at higher temperatures since the pickling of the steel is run at temperatures up to $60{ }^{\circ} \mathrm{C}$. The effect of temperature on the corrosion behavior of steel in presence of $1 \times 10^{-3} \mathrm{M}$ of compound II was studied in the temperature range $298-338 \mathrm{~K}$ as a representative example using the three different techniques. The electrochemical parameters again were collected at Table 4 . The results showed an increase in the inhibition efficiency with raising the solution temperature. This indicates physical adsorption of the inhibitors. The inhibition efficiency was found to increase with raising the solution temperature. This could be explained by the fact that at high temperatures the surface covered by the inhibitor increases and the rate determining step of the metal dissolution becomes the diffusion through the film of corrosion products and inhibitor. Inspection of the data reveals that an increase of temperature shifts the values of $\mathrm{E}_{\text {corr }}$ to more negative potentials. The values of $\mathrm{j}_{\text {corr }}$ increase with increasing temperature as a result of the higher dissolution of the metal at higher temperatures. The thermodynamic functions for the dissolution of steel in $1.0 \mathrm{M} \mathrm{HCl}$ in the absence and presence of compound II were obtained by applying the Arrhenius equation (3) and transition state equation (4), respectively, and the results are given in Table 5:

$$
\begin{aligned}
& \log \mathrm{j}_{\text {corr }}=\left(-\mathrm{E}_{\mathrm{a}} / 2.303 \mathrm{RT}\right)+\frac{\lambda}{\mathrm{j}_{\text {corr }}=\mathrm{RT} / \mathrm{Nh} \exp \left(\Delta \mathrm{S}_{\mathrm{a}} / \mathrm{R}\right) \exp \left(\Delta \mathrm{H}_{\mathrm{a}} / \mathrm{RT}\right)}
\end{aligned}
$$

where $E_{a}$ is the apparent activation energy, $R$ is the universal gas constant, $\lambda$ is the Arrhenius pre-exponential factor, $\Delta S_{a}$ is the change in entropy of activation, $\Delta \mathrm{H}_{\mathrm{a}}$ is the change in enthalpy of activation, $\mathrm{h}$ is Planck's constant and $\mathrm{N}$ is the Avogadro's number. According to eq. (3), the apparent activation energy $\mathrm{E}_{\mathrm{a}}$ can be obtained by plotting $\log \left(\mathrm{j}_{\text {corr }}\right)$ against $1 / \mathrm{T}$ (Fig. 5$)$. However, a plot of $\log \left(\mathrm{j}_{\text {corr }}\right.$ /T) against 1/T according to eq. (4) should give straight line with a slope of $\left(-\Delta \mathrm{H}_{\mathrm{a}}\right.$ $/ 2.303 \mathrm{R})$ and an intercept of $\left(\log \mathrm{R} / \mathrm{Nh}+\Delta \mathrm{S}_{\mathrm{a}} / 2.303 \mathrm{R}\right)$, as shown in Fig. 6. The value of the activation energy for the inhibited process is determined at the highest concentrations used, in order to assure that the achieved coverage degree is close to the maximal value. The activation energy, $\mathrm{E}_{\mathrm{a}}$, in case of steel, was found to be $46.9 \mathrm{~kJ} \mathrm{~mol}^{-1}$, in absence, and $29.9 \mathrm{~kJ} \mathrm{~mol}^{-1}$, in presence, of compound II. The value of the activation energy in presence of inhibitor is lower than in $1 \mathrm{M} \mathrm{HCl}$. Similar result of decreasing activation energy in presence of inhibitors has been previously reported by Popova et al. [27]. The preexponential factor in the Arrhenius equation, $\lambda$, for heterogeneous reaction, is related to the number of active centers [28]. These active centers have different energy, if energetic surface heterogeneity is assumed. There are two possibilities: in the first case $\left(\mathrm{E}_{\mathrm{a} \text {,inh }}\right.$ is greater than $\left.\mathrm{E}_{\mathrm{a}, \mathrm{HCl}}\right)$ the inhibitor is adsorbed on the most active adsorption sites (having the lowest energy) and the corrosion process takes place predominantly on the active sites of the higher energy. In the second case ( $E_{a, \text { inh }}$ is lower than $E_{a, H C l}$ ), observed in these experiments, the value of $\lambda$ is lower $\left(\lambda=4.46 \times 10^{-3}\right)$ than that in pure $\mathrm{HCl}(\lambda=0.0316)$, i.e., a smaller number of more active sites remain uncovered which take part in the corrosion process [29]. 


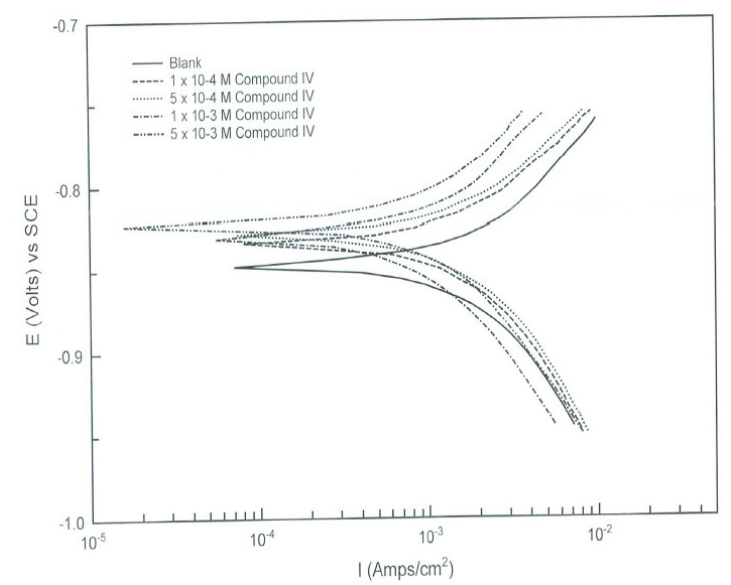

Figure 4. Potentiodynamic cathodic and anodic polarization scans for C-steel in $1.0 \mathrm{M}$ $\mathrm{HCl}$ in the absence and presence of different concentrations of compound IV.

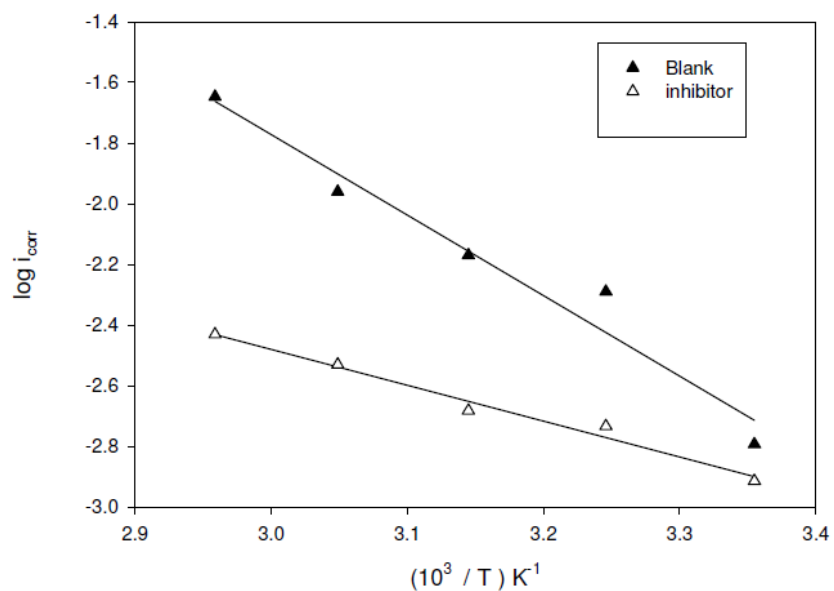

Figure 5. Arrhenius plots for $\mathrm{C}$-steel in $1 \mathrm{M} \mathrm{HCl}$ solution in the absence and presence of $1 \times 10^{-3} \mathrm{M}$ of compound II.

Table 4. Effect of temperature on the electrochemical parameters and the inhibition efficiencies in presence of $1 \times 10^{-3} \mathrm{M}$ of compound II determined from potentiodynamic polarization curves, linear polarization and weight loss methods.

\begin{tabular}{|c|c|c|c|c|c|c|c|c|c|}
\hline \multirow[b]{2}{*}{$\mathrm{T} / \mathrm{K}$} & \multicolumn{3}{|c|}{ Blank } & \multicolumn{3}{|c|}{ Blank $+1 \times 10^{-3} \mathrm{M}$ Compound II } & \multirow[b]{2}{*}{$\eta_{\text {pol }} \%$} & \multirow[b]{2}{*}{$\eta_{\mathrm{Rp}} \%$} & \multirow[b]{2}{*}{$\begin{array}{c}\eta_{\mathrm{WL}} \\
\%\end{array}$} \\
\hline & $\begin{array}{c}\mathrm{j}_{\text {corr }} \\
\left(\mathrm{A} / \mathrm{cm}^{2}\right)\end{array}$ & $\begin{array}{l}-E_{\text {corr }} \\
(\mathrm{mV})\end{array}$ & $\begin{array}{c}\mathrm{R}_{\mathrm{p}} \\
\left(\Omega / \mathrm{cm}^{2}\right)\end{array}$ & $\begin{array}{c}\mathrm{j}_{\text {corr }} \\
\left(\mathrm{A} / \mathrm{cm}^{2}\right)\end{array}$ & $\begin{array}{l}-\mathrm{E}_{\text {corr }} \\
(\mathrm{mV})\end{array}$ & $\begin{array}{c}\mathrm{R}_{\mathrm{p}} \\
\left(\Omega / \mathrm{cm}^{2}\right)\end{array}$ & & & \\
\hline 298 & 0.0016149 & 835.8 & 18.6 & 0.0012176 & 832.7 & 23.4 & 24.6 & 25.8 & 26.5 \\
\hline 308 & 0.0051448 & 877.9 & 11.6 & 0.0018486 & 864.4 & 18.9 & 64.1 & 62.9 & 65.7 \\
\hline 318 & 0.006769 & 881.1 & 9.5 & 0.0020797 & 873.8 & 16.0 & 69.2 & 68.4 & 69.9 \\
\hline 328 & 0.0069829 & 888.1 & 7.9 & 0.002025 & 878.7 & 13.5 & 71.0 & 70.9 & 71.5 \\
\hline 338 & 0.022523 & 895.2 & 5.9 & 0.005790 & 887.9 & 10.3 & 74.0 & 74.6 & 75.9 \\
\hline
\end{tabular}

Table 5. Thermodynamic parameters for $\mathrm{C}$-steel in $1 \mathrm{M} \mathrm{HCl}$ obtained from polarization measurements in presence of $1 \times 10^{-3} \mathrm{M}$ of compound II.

\begin{tabular}{cccc}
\hline$-\Delta \mathrm{S}_{\mathrm{a}}\left(\mathrm{J} \mathrm{mol}^{-1}\right)$ & $\Delta \mathrm{H}_{\mathrm{a}}\left(\mathrm{kJ} \mathrm{mol}^{-1}\right)$ & $\mathrm{E}_{\mathrm{a}}\left(\mathrm{kJ} \mathrm{mol}^{-1}\right)$ & \\
\hline 232.6 & 49.1 & 46.9 & Blank \\
132.7 & 20.0 & 29.9 & Compound II \\
\hline
\end{tabular}




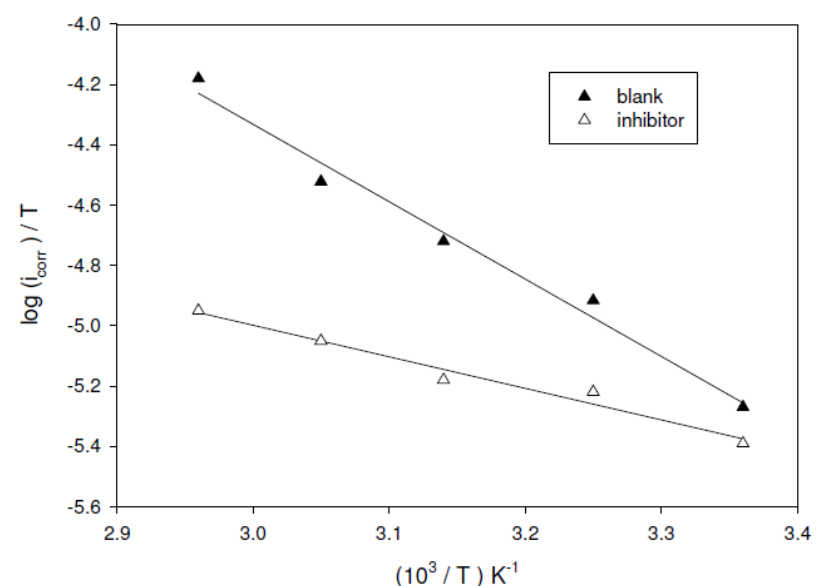

Figure 6. Plot of $\left.\left(\log \mathrm{i}_{\text {corr }}\right) / \mathrm{T}\right)$ vs. $10^{3} / \mathrm{T}$ for $\mathrm{C}$-steel in $1 \mathrm{M} \mathrm{HCl}$ in the absence and presence of $1 \times 10^{-3} \mathrm{M}$ of compound II.

The entropy of activation $\Delta \mathrm{S}_{\mathrm{a}}$ in the absence and presence of compound II is large and negative (Table 5). This implies that the activated complex in the rate determining step represents an association rather than a dissociation step, meaning that a decrease in disordering takes place on going from reactants to the activated complex [30]. The value of $\Delta \mathrm{Ha}$ reflects the strong adsorbabilty of the tested compound on the steel surface and indicates the endothermic nature of the process.

\section{Linear polarization measurements}

In order to determine the polarization resistance, $\mathrm{R}_{\mathrm{p}}$, the working electrode was polarized $\pm 10 \mathrm{mV}$ in the vicinity of the corrosion potential at a scan rate of 1 $\mathrm{mVs}^{-1}$. The polarization resistance values were determined from the slope of the current density-potential lines

$$
\mathrm{R}_{\mathrm{p}}=\mathrm{A} d E / d j
$$

where $\mathrm{A}$ is the surface area of the electrode, $d E$ is the change in potential and $d j$ is the change in current. The $R_{p}$ values were used to calculate the inhibition efficiencies, $\left(\eta_{\mathrm{Rp}} \%\right)$ using the relationship:

$$
\eta_{\mathrm{Rp}} \%=\left(1-\mathrm{R}_{\mathrm{p}} / \mathrm{R}_{\mathrm{p}}^{\mathrm{o}}\right) \times 100
$$

where $R_{p}$ and $R_{p}^{o}$ are the polarization resistance in the absence and presence of inhibitors, respectively. From Table 6 , it can be seen that by increasing the inhibitor concentration, both the polarization resistance and the inhibition efficiency increase, indicating adsorption of the inhibitors on the metal surface to block the active sites and inhibit corrosion. The inhibition efficiency again is seen to decrease in the following order, II > III > I > IV.

Obtained results from Tafel polarization, linear polarization and weight loss are in good agreement with each other. 
Table 6. Polarization resistances and inhibition efficiencies obtained from the linear polarization method for C-steel in $1.0 \mathrm{M} \mathrm{HCl}$.

\begin{tabular}{|c|c|c|c|c|c|}
\hline $\begin{array}{c}\text { Concentration } \\
\left(\mathrm{mol} \mathrm{dm}^{-3}\right)\end{array}$ & $\mathrm{R}_{\mathrm{p}}\left(\Omega / \mathrm{cm}^{2}\right)$ & $\eta_{\mathrm{Rp}} \%$ & $\begin{array}{c}\text { Concentration } \\
\left(\mathrm{mol} \mathrm{dm}^{-3}\right)\end{array}$ & $\mathrm{R}_{\mathrm{p}}\left(\Omega / \mathrm{cm}^{2}\right)$ & $\eta_{\mathrm{Rp}} \%$ \\
\hline $1 \mathrm{M} \mathrm{HCl}$ (blank) & 11.6 & - & Compound III & & \\
\hline Compound I & & & $1 \times 10^{-4}$ & 16.8 & 44.8 \\
\hline $1 \times 10^{-4}$ & 16.0 & 37.9 & $5 \times 10^{-4}$ & 18.8 & 62.1 \\
\hline $5 \times 10^{-4}$ & 16.2 & 39.6 & $1 \times 10^{-3}$ & 20.1 & 73.3 \\
\hline $1 \times 10^{-3}$ & 18.9 & 62.9 & $5 \times 10^{-3}$ & 20.8 & 79.3 \\
\hline $5 \times 10^{-3}$ & 19.8 & 70.7 & Compound IV & & \\
\hline Compound II & & & $1 \times 10^{-4}$ & 17.2 & 48.3 \\
\hline $1 \times 10^{-4}$ & 15 & 29.3 & $5 \times 10^{-4}$ & 17.9 & 54.3 \\
\hline $5 \times 10^{-4}$ & 16.8 & 44.8 & $1 \times 10^{-3}$ & 18.7 & 61.2 \\
\hline $1 \times 10^{-3}$ & 18.6 & 60.3 & $5 \times 10^{-3}$ & 19.7 & 69.8 \\
\hline $5 \times 10^{-3}$ & 20.9 & 79.9 & & & \\
\hline
\end{tabular}

\section{Adsorption isotherm}

Basic information dealing with the interaction between the inhibitor molecules and the metal surface can be provided by adsorption isotherms [31]. In order to get more knowledge about the mode of adsorption of ILs on the surface of the steel, the data obtained from the potentiodynamic polarization curves have been tested with the well known adsorption isotherms. Data obtained from polarization measurements were tested graphically for fitting various isotherms including Langmuir, Frumkin and Temkin. Among these isotherms, the best fit was obtained with the Langmuir isotherm. According to this isotherm $\theta$ is related to the inhibitor concentration by the following equation:

$$
\mathrm{c} / \Theta=\left(1 / \mathrm{K}_{\mathrm{ads}}\right)+\mathrm{c}
$$

where $\mathrm{c}$ is the inhibitor concentration in $\mathrm{mol} \mathrm{dm} \mathrm{dm}^{-3}, \Theta$ is the degree of surface coverage $(\theta=\eta / 100)$ and $K_{a d s}$ is the equilibrium constants of adsorption process. It is noted that the straight lines obtained on plotting $\mathrm{c} / \Theta \mathrm{vs}$. $\mathrm{c}$, as shown in Fig.7, suggest that the adsorption of the ILs inhibitors on the steel surface in $\mathrm{HCl}$ solution follows Langmuir's adsorption isotherm. The degree of surface coverage was found to increase with increasing the concentration of additive.

The free energy of adsorption $\left(\Delta \mathrm{G}_{\mathrm{ads}}\right)$ was calculated from the equation [32]:

$$
\Delta \mathrm{G}_{\mathrm{ads}}=-\mathrm{RT} \ln \left(55.5 \mathrm{~K}_{\mathrm{ads}}\right)
$$

where $55.5 \mathrm{~mol} \mathrm{dm}^{-3}$ is the molar concentration of water in the solution, $\mathrm{R}$ is the gas constant and $\mathrm{T}$ is the absolute temperature. Generally, values of $\Delta \mathrm{G}_{\mathrm{ads}}$ up to $20 \mathrm{~kJ} \mathrm{~mol}^{-1}$ are consistent with electrostatic interactions between the charged molecules and the charged metal (physisorption), while those around $-40 \mathrm{~kJ} \mathrm{~mol}^{-1}$ or higher are associated with chemisorption as a result of sharing or transfer of electrons from ILs molecules to the metal surface to form a coordinate type of bond (chemisorption) [33]. The absolute values of $\Delta \mathrm{G}_{\mathrm{ads}}$ calculated in presence of the four ILs inhibitors are found to be relatively small (around $30 \mathrm{kJmol}^{-1}$ ). 


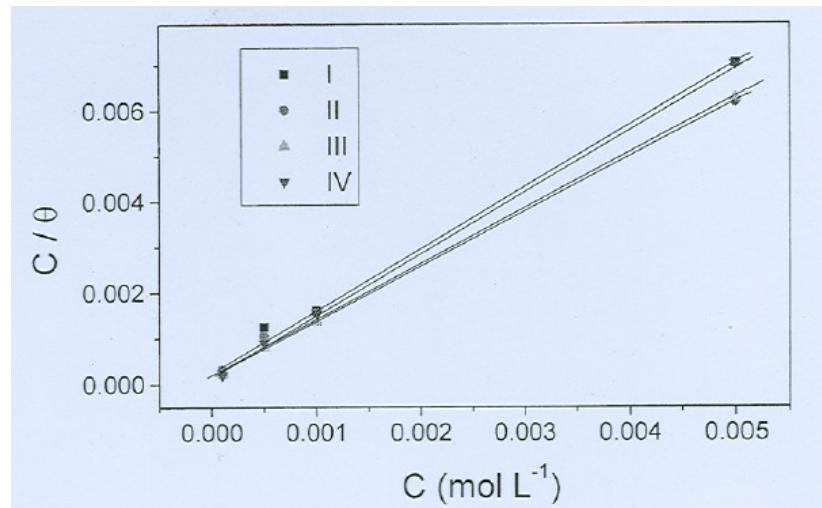

Figure 7. Langmuir isotherm for the adsorption of compounds I, II, III and IV by using Tafel polarization method.

Therefore, the results indicate the inhibitors to be physically adsorbed on the surface and their negative sign indicates spontaneous interaction of inhibitor molecule with the corroding steel surface [34]. In general, all the inhibitors used in this study have two nitrogen atoms in their molecular structure. These two nitrogen atoms could be in one ring, e.g., imidazolium compounds (I and II) or in two different rings, e.g., pyridinium compounds (compounds III and IV). Adsorption can occur through the formation of an iron-nitrogen coordinate bond or $\pi$-electron interaction between the heterocyclic in their molecules with aromatic character and the iron substrate. Adsorption can also occur via electrostatic interactions between a negatively charged surface (due to the specific adsorption of $\mathrm{Br}^{-}$anion on the steel surface) and the positive charge of the cationic molecules. In addition, electrostatic interactions could be achieved due to the ionic liquid compounds and the solid surfaces which can play a role in the adsorption process. Comparing compounds I and II, the latter is characterized by the presence of benzene ring instead of $-\mathrm{CH}_{2}-\mathrm{COEt}$ group in compound $\mathrm{I}$. Therefore, compound II has a higher rate of relaxation of the adsorbed inhibitors from the metal surface because of the flat aromatic head groups that can $\pi$-back bond with $\mathrm{Fe}^{2+}$.

In the case of compounds III and IV, i.e., pyridinium compounds, it was found that shorter chain for pyridinium compounds (Compound III) raised values of $\Theta$ and consequently $\eta \%$. The compound of pyridinium participates in a more parallel rather than perpendicular orientation at the surface, due to the presence of two flat aromatic head groups that can $\pi$-back bond with $\mathrm{Fe}^{2+}$. Thus, the adsorbed molecule would occupy a larger surface area compared with a perpendicular orientation which is the reason for high $\eta \%$ of compound III in comparison with compound IV.

\section{Surface morphology study}

The surface morphologies of C-steel specimen in $1.0 \mathrm{M} \mathrm{HCl}$ solution free or containing some of the ILs inhibitors after $4 \mathrm{~h}$ immersion were examined using scanning electron microscopy (SEM), as displayed in Fig. 8a-c. In the absence of inhibitors (Fig. 8a), a very rough surface was observed due to rapid corrosion attack of carbon steel by chloride anions. There are a large number of pits 
surrounded by iron oxide layer which almost fully covers the carbon steel surface, revealing that pit formation under these conditions occurs continuously during the exposure period while iron oxide builds up over the surface. It is important to stress out that when ILs inhibitors (II and III) are present in the solution (Fg. 8b,c), the morphology of the carbon steel surface is quite different from the previous one and the rough surface (amount of the formed iron oxide and the number of pits) is visibly reduced, indicating the formation of a protective film.

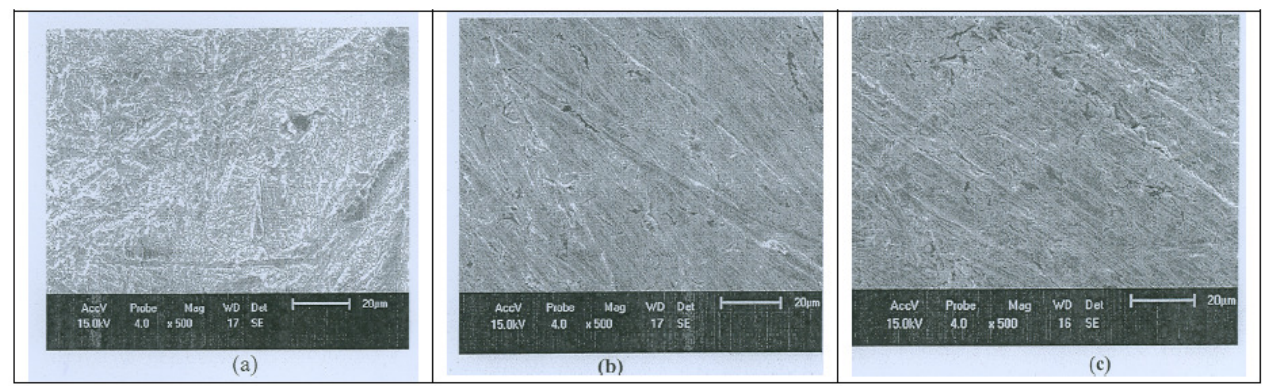

Figure 8. SEM micrographs of the surface of the C-steel specimens in $1.0 \mathrm{M} \mathrm{HCl}$ in absence (a), and in presence of $1 \times 10^{-3} \mathrm{M}$ of compound II (b) and $1 \times 10^{-3} \mathrm{M}$ of III (c).

\section{Conclusion}

From the overall experimental results and discussion the following conclusions can be deduced:

- The four tested ILs behave as inhibitors for the corrosion of the C-steel in $1 \mathrm{M} \mathrm{HCl}$ solution.

- The inhibition efficiency increased with increasing the inhibitor concentration. All of the ILs act as mixed-type inhibitors.

- The inhibition is due to the adsorption of the inhibitor molecules on the Csteel surface and the blocking of active sites.

- Obtained results from Tafel polarization, linear polarization and weight loss are in good agreement with each other.

- The adsorption of the four ILs inhibitors obeys the Langmuir adsorption isotherm.

\section{Acknowledgements}

The authors gratefully acknowledge the financial support from Taibah University (Grant 430/417).

\section{References}

1. I. Ahamad, C. Gupta, R. Prasad, M.A. Quraishi, J. Appl. Electrochem. 40 (2010) 2171.

2. F. El-Taib Heakal, A.S. Fouda and M.S. Radwan, Mater. Chem. Phys. 125 (2011) 26. 
3. B. Mernari, H. Elattari, M. Traisnel, F. Bentiss, M. Lagrenee, Corrosion 40 (1998) 391.

4. S.S. Abd El Rehim, Magdy A.M. Ibrahim, K.F. Khaled, Mater. Chem. Phys. 70 (2001) 268.

5. M.M. Hamza, S.S. Abd El Rehim and Magdy A.M. Ibrahim, Arab. J. Chem. (in press).

6. S.S. Abd El Rehim, Magdy A.M. Ibrahim and K.F. Khaled, J. Appl. Electrochem. 29 (1999) 593.

7. K.F. Khaled, A.El-mghraby, O.B. Ibrahim, O.A. Elhabib, Magdy A.M. Ibrahim, J. Mater. Environ. Sci. 1(3) (2010) 139.

8. I. Sekine, Y. Nakata, H. Tanabe, Corros. Sci. 28 (1988) 987.

9. A. Popova, M. Christov, S. Raicheva, E. Sokolova, Corros. Sci. 46 (2004) 1333.

10. A. Popova, M. Christov, T. Deligeorgiev, Corrosion 59 (2003) 756.

11. A. Popova, E. Sokolova, S. Raicheva, M. Christov, Corros. Sci. 45 (2003) 33.

12. A. Popova, M. Christov, Corros. Sci. 48 (2006) 3208.

13. T. Tsuda, C.L. Hussey, Interface 16 (2007) 42.

14. S. Zhang, N. Sun, X. He, X. Lu, X. Zhang, J. Phys. Chem. Ref. Data 35 (2006) 4.

15. H. Zhao, Chem. Eng. Comm. 193 (2006) 1660.

16. H. Ashassi-Sorkhabi, M. Es'haghi, Mater. Chem. Phys. 114 (2009) 267.

17. N.V. Likhanova, M.A. Dominguez-Aguilar, O. Olivares-Xometl, N. NavaEntzana, E. Arce, H. Dorantes, Corros. Sci. 52 (2010) 2088.

18. Q.B. Zhang, Y. X. Hua, Electrochim Acta 54 (2009) 1881.

19. R. Gasparac, C.R. Martin, E. Stupnisek-lisek, J. Electrochem. Soc. 147 (2000) 548.

20. S. Muralidharan, S.V.K. Lyer, Anti-Corros. Methods Mater. 44 (1997) 100.

21. M.E. Palomar, C.O. Olivares-Xometl, N.V. Likhanova, J.B. PerezNavarrete, J. Surfact. Deterg. 14 (2011) 211.

22. M.A. Quraishi, M.Z.A. Rafique, S. Khan, N. Saxena, J. Appl Electrochem. 37 (2007) 1153.

23. J. Beata, K. Janina, P. Jerzy, Dyes and Pigments 73(3) (2006) 361.

24. Sk.A. Ali, M.T. Saeed, S.U. Rahman, Corros. Sci. 45 (2003) 253.

25. M.M. Saleh, A.A. Atia, J. Appl. Electrochem. 36 (2006) 899.

26. E.S. Ferreira, C. Giacomelli, F.C. Giacomelli, A. Spinelli, Mater. Chem. Phys. 83 (2004) 129.

27. A. Popova, M. Christov, Corros. Sci. 48 (2006) 3208.

28. P.W. Atkins, Physical Chemistry, Mir, Moscow, 1980.

29. A. Popova, M. Christov, A. Vasilev, Corros. Sci. 49 (2007) 3276.

30. M.K. Gomma, M.H. Wahdan, Mater. Chem. Phys. 39 (1995) 209.

31. E. McCafferty, in: H. Leidheister Jr. (Ed.), Corrosion Control by Coating, Science Press, Princeton, 1979, p. 279.

32. J.M. Cases, F. Villieras, Langmuir 8 (1992) 1251.

33. S.A. Umoren, E.E. Ebenso, Mater. Chem. Phys. 106 (2007) 393.

34. M. Abdullah, Corros. Sci. 44 (2002) 717. 